\title{
Effect of Neck Rotating Directions on the Muscle Activity of Upper and Lower Trapezius during Shoulder External Rotation
}

\author{
Yong Wook Shin', Chi Hwan Kim', Jin Tae Han² \\ 'Department of Physical Therapy, Graduate School, Kyungsung University, Busan; ${ }^{2}$ Department of Physical Therapy, College of Science, Kyungsung \\ University, Busan, Korea
}

Purpose: This study examined the effects of the directions of neck rotation on the muscle activity of the upper trapezius and lower trapezius while rotating a shoulder externally.

Methods: Twenty-five healthy males participated in this study. The subjects were asked to rotate their shoulder externally with $90^{\circ}$ shoulder abduction and $90^{\circ}$ elbow flexion in three different neck rotations (neutral, ipsilateral, and contralateral) in the prone position. The muscle activities of the upper and lower trapezius were measured using surface electromyography. One way repeated measures ANOVA was used to compare the muscle activity of the upper and lower trapezius depending on the different neck turning directions.

Results: In the upper trapezius, turning the neck in the ipsilateral direction while turning a shoulder externally decreased the muscle activity significantly, but the muscle activity was increased significantly by turning the neck in the contralateral direction. On the other hand, in the lower trapezius, turning the neck in the ipsilateral direction increased the muscle activity significantly, but the muscle activity was decreased significantly by turning the neck in the contralateral direction decreased it significantly.

Conclusion: When someone has an imbalance of shoulder function, turning the neck in the ipsilateral direction while turning the shoulder externally in the prone position is effective in decreasing the activity of the upper trapezius and increasing the activity of the lower trapezius. Therefore, these results could be used as basic evidence for researching patients with shoulder problems.

Keywords: Shoulder external rotation, Neck rotation, Trapezius activity, Muscle unbalance

\section{서 론}

구부정한 자세로 일하는 사무직 종사자들은 목의 앞기울임이 발생 되고, 등은 뒤로 굽은 자세가 되어 어깨 근육의 불균형을 일으키며, 특히 아래등세모근의 약화로 어깨통증이 발생할 수 있다. 또한 아래 등세모근의 약화는 작은가슴근을 단축시키고 어깨뼈의 앞쪽기울임 을 발생시켜 어깨뼈의 정상적인 정렬을 벗어나게 하며 어깨뼈 위쪽 돌림을 동반한 어깨뼈 올림을 일으켜 위등세모근이 과활성화되게 한다. 따라서 아래등세모근이 약화되면 어깨뼈를 위쪽 돌림시키는 근육의 불균형을 초래하고, 이로 인해 비정상적인 어깨위팔리듬 (scapulohumeral rhythm)이 발생하여 효율적인 위팔 기능을 수행할 수 없다. ${ }^{2}$ 약화된 아래등세모근은 어깨뼈의 역학적인 문제를 일으킬 수 있으며 어깨의 불안정성을 초래할 수 있다. ${ }^{3,4} \mathrm{Ki}$ 등 5 은 아래등세모 근이 약화되었을 때 어깨뼈 위쪽 돌림을 동반한 어깨관절 올림이 발
생하고, 위등세모근의 과활동(hyper-activation)을 유발시켜 반복적으 로 물체를 들어 올리는 작업을 하는 작업자 및 환자의 등세모근에 만 성적인 근육통을 유발시키는 원인이 될 수 있다고 하였다. 아래등세 모근의 약화와 위등세모근의 과활성화와 같은 등세모근의 불균형은 오십견(frozen shoulder)과 충돌증후군(impingement syndrome) 환자 들에게 흔히 나타난다고 하였다. ${ }^{6,7}$

어깨수술이나 급성 어깨손상 등으로 인한 재활운동 초기에 어깨 뼈의 안정화를 위한 어깨뼈 내림 운동은 운동 범위의 개선과 관절 부 하에 대한 조절이 용이하기 때문에 재활훈련에서 많이 사용되고 있 다. ${ }^{8}$ 위등세모근의 근활성도를 최소화하면서 아래등세모근과 앞톱 니근의 반응을 이끌어내는데 효과적이라고 하였다. ${ }^{9}$ Decker 등 ${ }^{10}$ 은 어 깨뼈 위쪽돌림근들을 효율적으로 사용하기 위해서 위등세모근의 근활성도는 낮추면서 아래등세모근의 근활성도를 증가시키는 것이 필요하다고 보고하였다. 여러 가지 아래등세모근 강화 운동이 제시 
되고 있으며, 특히 슈퍼맨 자세와 같은 엎드린 자세에서 팔을 $145^{\circ}$ 벌 림하여 팔을 위로 들어올리는 운동(prone arm lift, PAL)이 아래등세 모근의 근력 강화에 많은 영향을 미친다고 하였다.1 하지만 엎드린 자 세에서 팔들어올리기 운동은 위등세모근의 근활성도를 크게 증가시 키기 때문에 위등세모근의 과활성화 증상이 있는 경우에는 적합하 지 않을 수 있다고 하였다. ${ }^{12}$ Cools 등 ${ }^{13}$ 의 연구에 따르면, 엎드린 자세 에서 팔을 위로 올리는 운동은 목과 어깨에 근육불균형이 있을 경 우, 팔을 벌리는 동안 어깨뼈의 위쪽 돌림과 내림 대신에 어깨뼈의 올 림을 유발한다고 하였다. 또한 Choi 등은 상위교차증후군(upper cross syndrome)이 있는 경우 작은가슴근(pectoralis minor)의 단축으 로 인해 엎드린 자세에서 팔을 위로 올리는 동작은 어깨관절의 손상 이나 통증 등 이차적인 문제를 발생시킬 수 있다고 하였다. 어깨에 병 리적인 문제를 가진 환자들에게는 엎드린 자세에서 팔을 들어올리 는 운동은 적용하기 어려울 수 있기 때문에 어깨를 $90^{\circ}$ 벌린 상태에 서 어깨 가쪽돌림 운동을 하는 것이 아래등세모근의 근활성도를 높 일 수 있는 방법이라고 하였다. ${ }^{14}$ 또한 선 자세와 비교하여 엎드린 자 세에서 어깨가쪽돌림 운동을 실시하였을 때 상대적으로 위등세모 근의 근활성도는 낮아지고 아래등세모근의 근활성도는 높아졌다. ${ }^{15}$ 엎드린 자세에서 어깨가쪽돌림 운동은 어깨 굽힘이나 벌림 $90^{\circ}$ 이하 에서 운동이 필요한 대상자에게 아래등세모근을 선택적으로 강화시 킬 수 있는 운동 방법이며 초기 어깨 재활에서 어깨돌림근을 함께 강 화시킬 수 있는 효과적인 방법이라고 하였다. ${ }^{14}$ Park 등 ${ }^{16}$ 은 엎드린 자 세에서 팔 들어올리기운동 중 목을 같은 방향으로 돌렸을 경우에 위 등세모근의 근활성도가 유의하게 감소되었다고 하였다. Kendall 등 ${ }^{17}$ 은 목을 반대 방향으로 돌렸을 때 위등세모근이 크게 작용한다고 하 였다. 또한 Hwang 등 ${ }^{18}$ 은 위등세모근이 목을 반대쪽으로 돌리는데 작용하며 지금까지 목의 돌림 방향에 따른 등세모근의 근활성도 변 화를 연구한 선행연구들의 결과에서 대부분 목의 반대쪽 돌림에서 위등세모근의 근활성도가 증가하는 결과가 나타났다. Kim 등19은 침 전극을 사용하여 위등세모근의 활동전위를 측정하는 연구를 실시 하였는데 목을 같은쪽으로 돌림하였을 때 위등세모근의 활동전위가 증가하였다고 하였다.

어깨뼈 돌림 장애에 관한 선행연구들은 앞톱니근과 아래등세모근 의 근활성도 감소와 위등세모근의 과활성화를 원인으로 보고하고 있으며 이러한 문제에 대한 해결방안으로 아래등세모근의 선택적인 강화를 권장하고 있다. ${ }^{20}$ 하지만 엎드린 자세에서 어깨 가쪽돌림 운 동을 할 경우, 보다 안전하고 효과적으로 위등세모근의 과활성도를 감소시키고 아래등세모근을 선택적으로 강화할 수 있는 방법을 알 아보는 연구는 많이 이루어지지 않았다. 그리고 목의 돌림 방향(중립 방향, 동측방향, 반대방향)에 따른 위등세모근과 아래등세모근의 근 활성도에 대한 과학적 근거가 아직 부족한 실정이다. 따라서 본 연구
는 어깨가쪽돌림 시 목의 돌림 방향에 따라 위등세모근과 아래등세 모근의 근활성도 변화를 알아보고 임상에서 선택적으로 위등세모근 의 과활동성은 감소시키고 아래등세모근의 근활성도를 높이는 효 과적인 중재 방법을 찾아보고자 하였다.

\section{연구 방법}

\section{1. 연구대상자}

본 연구는 연구의 목적을 충분히 이해하는 건강한 남자 성인 25 명을 대상자로 하였다. 대상자에게 연구에 대한 사전 설명과 동의서를 제 공하였고 자발적인 참여와 동의서를 받았다. 그리고 본 연구는 $\mathrm{K}$ 대 학교의 생명윤리위원회에 의해 연구윤리승인을 받아 실험을 수행하 였다(KSU-18-12-003). 대상자의 선정기준은 실험에 요구되는 정상 근 력과 관절운동범위를 가지고 있는 자, 신경학적. 정형외과적 병력이 없는 자로 하였으며 목과 어깨에 근육통이 있는 자, 목뼈 수술을 한 병력이 있는 자, 선천적 및 후천적 기형이 있는 자, 정신적 질환이 있 는 자, 디스크 질환이 있는 자, 그리고 여성은 제외하였다. 여성을 제 외한 이유는 남성과 여성의 근력 차이가 크기 때문에 측정값의 편차 를 줄이기 위함이었다. ${ }^{21}$

\section{2. 측정방법}

\section{1) 측정도구}

어깨가쪽돌림 시 목의 돌림 방향에 따라 위등세모근과 아래등세모 근의 근활성도를 측정하고 분석하기 위해 표면 근전도(TeleMyo DTS, Noraxon Inc., USA)를 사용하였다. 표면 전극을 부착하기 전 피부 저 항을 줄이기 위하여 사포로 피부 각질을 제거하고 필요에 따라 털을 면도하여 알코올 솜으로 충분히 피부를 닦아낸 다음 전극 부위를 완 전히 건조한 후 전극을 피부에 부착하였다..$^{22}$ 근전도 신호의 표본추 출률(sampling rate)은 $1,024 \mathrm{~Hz}$ 로 설정하였고, $60 \mathrm{~Hz}$ 여과필터(notch filter)를 사용하였으며, 주파수 대역폭은 $20-450 \mathrm{~Hz}$ 를 사용하였다. 그 리고 수집된 근전도 자료는 RMS 처리하였고, 노이즈를 제거하기 위 해 전파 정류(full wave rectification)를 하였다. 2 채널을 이용하여 위등 세모근과 아래등세모근에 표면 전극을 부착하였고 전극은 엎드려 누운 자세에서 우세측에 부착하였다. 위등세모근의 전극 부착 부위 는 7번 목뼈의 가시돌기에서 어깨뼈봉우리의 위쪽 끝의 중간지점이 고, 아래등세모근의 전극부착부위는 어깨뼈 가시 안쪽 모서리부분 에서 아래 안쪽 $55^{\circ}$ 각도로 비스듬한 사선방향으로 $5 \mathrm{~cm}$ 지점으로 어 깨뼈 안쪽 모서리 바로 옆에 부착하여 근활성도 자료를 수집하였 다. ${ }^{23}$ 위등세모근과 아래등세모근의 최대 자발적 등척성 수축(maximum voluntary isometric contraction)을 사용하여 각 근육에 대해 근 전도 신호 값을 표준화하였다. ${ }^{14}$ 위등세모근과 아래등세모근의 최대 

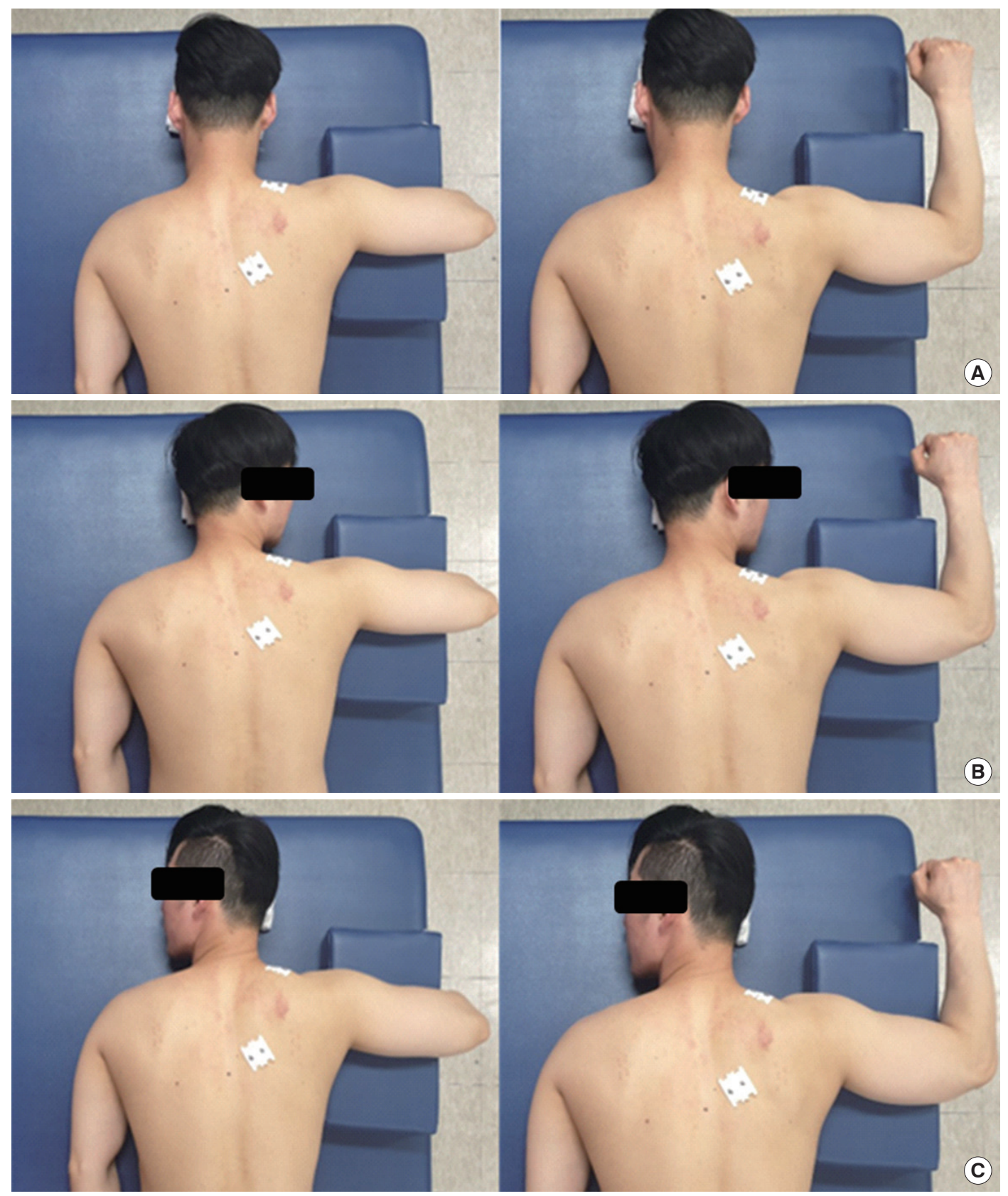

Figure 1. Directions of neck rotation during shoulder external rotation. (A) Neutral neck position, (B) Ipsilateral neck rotation, (C) Contralateral neck rotation.

자발적 등척성 수축을 위한 대상자의 자세는 표준화 된 맨손근력자 세에서 실시하였다. ${ }^{17}$ 각 근육의 최대 자발적 등척성 수축 값은 3 번 측 정하여 평균값을 구하였으며, 최대 자발적 등척성 수축 시 5 초 동안 의 자료값을 구하여 처음과 끝부분의 각 1 초를 제외한 3 초 동안의 평 균 근전도 신호 값을 최대 자발적 근수축 값으로 사용하였다. ${ }^{14}$ 그 후 에 최대 자발적 수축에 대한 각 목의 돌림 방향에 따른 어깨가쪽돌 림 시 근활성도 값의 비율을 계산하여 \%MVIC를 산출하였다.

\section{2) 실험절차}

어깨가쪽돌림 시 목의 돌림 방향(neutral, ipsilateral, contralateral)에 따 른 위등세모근과 아래등세모근의 근활성도를 측정하기 위해 엎드린 자세에서 어깨벌림 $90^{\circ}$, 팔꿉 굽힘 $90^{\circ}$ 한 상태에서 어깨가쪽돌림을 5 초간 유지하도록 하였다. 이때 기록되는 위등세모근과 아래등세모근 의 근전도 신호를 수집하였다. 대상자가 정확한 동작을 수행할 수 있 도록 관절 각도는 관절각도계(goniometer)를 사용하여 검사 자세를 설정하였다. ${ }^{14}$ 운동 자세는 근 피로를 최소화하기 위하여 반복 측정 
전에는 1 분의 휴식시간을 주었으며 목의 돌림 위치를 변경할 때 동작 수행 전에는 10 분간 휴식시간을 제공하였다.

\section{3. 통계분석}

어깨가쪽돌림 시 목의 돌림 방향에 따른 위등세모근과 아래등세모 근의 근활성도 차이를 알아보기 위해 일요인 반복측정분산분석(one way repeated measures ANOVA)을 사용하였다. 각 근육의 근활성도에 대한 평균값과 표준편차를 산출하여 제시하였다. 목의 돌림 방향에 따른 위등세모근과 아래등세모근의 근활성도에 대한 유의성은 대응 별비교를 이용하여 분석하였다. 통계 프로그램은 SPSS 25 (IBM SPSS Statistics)를 사용하고, 유의수준은 $\alpha=0.05$ 로 설정하였다.

\section{결 과}

\section{1. 연구대상자의 일반적 특성}

본 연구의 대상자는 남자 25 명으로 평균 연령은 $26.35 \pm 5.44$ 세, 평균 신장은 $172.76 \pm 6.70 \mathrm{~cm}$, 평균 체중은 $68.15 \pm 8.34 \mathrm{~kg}$ 이었다(Table 1).

\section{2. 어깨가쪽돌림 시 목의 돌림 방향에 따른 위등세모근과 아래등세모근의 근활성도 비교}

어깨가쪽돌림 시 목의 돌림 방향에 따른 위등세모근의 근활성도는 대체적으로 목을 중립방향으로 했을 때보다 같은 쪽 방향으로 돌렸 을 때 감소되었고 반대쪽 방향으로 돌렸을 때 증가하였고 통계적으 로 유의한 차이가 있었다 $(\mathrm{p}<0.05)$. 대응별비교에서 목을 중립방향으 로 했을 때와 비교하여 목을 같은 쪽 방향으로 돌렸을 때 위등세모근 의 근활성도는 통계적으로 유의하게 감소하였고 목을 중립방향으로 했을 때와 비교하여 목을 반대쪽 방향으로 돌렸을 때 위등세모근의 근활성도는 통계적으로 유의하게 증가하였다 $(\mathrm{p}<0.05)$ (Table 2).

어깨가쪽돌림 시 목의 돌림 방향에 따른 아래등세모근의 근활성 도는 대체적으로 목을 중립방향으로 했을 때보다 같은 쪽 방향으로 돌렸을 때 증가하였고 반대쪽 방향으로 돌렸을 때 감소하였고 통계 적으로 유의한 차이가 있었다 $(\mathrm{p}<0.05)$. 대응별비교에서 목을 중립방 향으로 했을 때와 비교하여 목을 같은 쪽 방향으로 돌렸을 때 아래등 세모근의 근활성도가 다소 증가하는 양상을 보였으나 통계적으로

Table 1. General characteristics of subjects

$(n=25)$

\begin{tabular}{lr}
\hline Variables & \multicolumn{1}{c}{ Subjects } \\
\hline Age $(\mathrm{yr})$ & $26.35 \pm 5.44$ \\
Height $(\mathrm{cm})$ & $172.76 \pm 6.70$ \\
Weight $(\mathrm{kg})$ & $68.15 \pm 8.34$ \\
BMI $\left(\mathrm{kg} / \mathrm{m}^{2}\right)$ & $22.83 \pm 2.16$ \\
\hline
\end{tabular}

BMl: body mass index.
유의한 차이는 없었고, 목을 중립방향으로 했을 때와 비교하여 목을 반대쪽 방향으로 돌렸을 때 아래등세모근의 근활성도가 크게 감소 하였고 통계적으로 유의한 차이가 있었다 $(\mathrm{p}<0.05)($ Table 2).

\section{고 찰}

많은 선행연구에서 어깨의 병리적인 문제가 있는 대상자에게 위등세 모근의 과활성화와 아래등세모근의 약화와 같은 근육불균형이 나 타난다고 보고하였다.6,22 Renoid 등 ${ }^{24}$ 은 위등세모근에 비해 아래등세 모근의 근활성도를 증가시키는 운동이 근육불균형을 감소시키고 자 세 개선에 도움이 된다고 하였다. 엎드린 자세에서 어깨가쪽돌림 운 동은 어깨뼈 내림을 유도하여 아래등세모근을 강화시키는 운동 방 법이다. ${ }^{12}$ 본 연구는 정상인을 대상으로 엎드린 자세에서 어깨가쪽돌 림 운동을 실시할 때 근전도를 활용하여 목의 돌림 방향이 위등세모 근과 아래등세모근의 근활성도에 어떤 영향을 미치는지 알았다. 그 리고 위등세모근의 과활성도는 감소시키고 아래등세모근을 선택적 으로 강화할 수 있는 효과적인 중재 방법을 제안하고자 하였다.

본 연구에서 위등세모근의 근활성도 분석결과, 엎드린 자세에서 어깨가쪽돌림 운동을 할 때 목을 같은 쪽 방향으로 돌렸을 때 중립 방향과 비교하여 근활성도가 감소하였고 목을 반대쪽 방향으로 돌 렸을 때 중립방향과 비교하여 근활성도가 크게 감소하였다. 선행연 구에서 팔들어올리기 운동 시 목을 같은 쪽 방향으로 돌렸을 때가 목을 중립방향으로 했을 때보다 위등세모근의 근활성도가 크게 감 소한다고 하였다.16 이는 본 연구와 유사한 결과이며, 목을 같은 쪽 방 향으로 돌렸을 때 위등세모근의 길이가 길어지기 때문이라고 생각되 어진다. 또한 엎드린 자세에서 어깨가쪽돌림 운동 시 목을 반대쪽으 로 돌릴 경우 위등세모근의 길이는 목을 중립방향으로 하였거나 같 은쪽 방향으로 돌릴 때보다 근육의 길이가 짧아지기 때문에 상대적 으로 위등세모근의 근활성도가 증가하였다. ${ }^{17}$ 그러므로 위등세모근 이 목의 반대쪽 돌림에 주로 작용하며 어깨뼈 내림을 할 때 어깨뼈 내 림근의 대항근으로 사용된다는 선행연구의 주장을 뒷받침할 수 있 는 근거라고 생각된다.

본 연구에서 아래등세모근의 근활성도 분석결과, 엎드린 자세에서 어깨가쪽돌림 운동 시 아래등세모근의 근활성도는 목을 중립방향

Table 2. Comparison of muscle activity of the trapezius depending on neck rotation directions

(\%MVIC)

\begin{tabular}{lcccc}
\hline \multirow{2}{*}{ Muscle } & \multicolumn{3}{c}{ Neck rotating directions $(n=25)$} & \multirow{2}{*}{$F$} \\
\cline { 2 - 4 } & Neutral & Ipsilateral & Contralateral & \\
\hline Upper trapezius & $13.80 \pm 10.80$ & $6.31 \pm 2.11^{*}$ & $23.81 \pm 19.12^{+}$ & 11.72 \\
Lower trapezius & $30.06 \pm 15.74$ & $34.85 \pm 18.06^{*}$ & $26.84 \pm 14.04^{+}$ & 10.38 \\
\hline
\end{tabular}

${ }^{*} \mathrm{p}<0.05$ : significant difference between neutral and ipsilateral neck rotation; $\mathrm{p}<0.05$ : significant difference between neutral and contralateral neck rotation. 
으로 했을 때 보다 같은 쪽 방향으로 돌렸을 때 대체로 증가하는 양 상을 보였지만 유의한 차이는 나타나지 않았다. 하지만 목을 반대쪽 방향으로 돌렸을 때 유의하게 감소하였다. Park 등16은 엎드린 자세에 서 팔들어올리기 운동 시 목을 중립방향으로 했을 때와 같은 쪽방향 으로 돌렸을 때 아래등세모근의 근활성도는 차이가 없었다고 하였 다. 이는 엎드린 자세에서 어깨가쪽돌림 운동 시 목을 같은 쪽 방향으 로 돌렸을 때 어깨뼈 내림에 대해 위등세모근이 더 크게 작용했기 때 문에 상대적으로 아래등세모근의 작용이 줄어든 것으로 생각된다. 또한 근육이 수축하고 있는 상태에서 근육 길이가 늘어나게 되면 근 장력(muscle tension)이 높아져 뺏뺏함(stiffness)이 증가하므로 ${ }^{25}$ 엎드 린 자세에서 어깨가쪽돌림 운동 시 목을 같은쪽으로 돌렸을 때가 반 대쪽으로 돌렸을 때보다 어깨올림근이 짧아지고 긴장도가 높아진다. 이러한 이유로 아래등세모근의 동원이 상대적으로 증가하여 근활성 도가 높아지는 것으로 생각된다. 결과적으로 본 연구에서 어깨가쪽 돌림 운동 시 목을 같은쪽으로 돌렸을 때 중립방향이나 반대쪽 방향 으로 돌렸을 때보다 아래등세모근의 근활성도가 위등세모근 보다 상대적으로 높게 나타났다.

선행연구에서 최대 등척성 운동을 실시할 때 근육의 길이가 짧은 경우에는 근활성도가 증가하고 근육의 길이가 늘어난 상태에서는 근활성도가 감소하였다고 보고하였다. ${ }^{26}$ 본 연구의 결과 역시 어깨가 쪽돌림 운동 시 목을 반대쪽 방향으로 돌렸을 때 위등세모근의 길이 는 짧아져서 근활성도가 증가하고 아래등세모근의 길이는 늘어나서 근활성도가 감소한 것으로 생각된다. 반대로 목을 같은 쪽 방향으로 돌렸을 때 위등세모근의 길이는 늘어나서 근활성도가 감소하고 아래 등세모근의 길이는 짧아져서 근활성도가 증가한 것으로 생각된다. 본 연구의 제한점은 첫째, 건강한 젊은 남자 성인을 대상으로 연구하 였기 때문에 여성이나 병리적인 문제를 가지고 있는 대상자는 반영 하지 못하였다. 따라서 연구결과의 해석이 제한적이다. 둘째, 위등세 모근과 아래등세모근의 근활성도만 조사하였기 때문에 목의 돌림에 관여하는 주변 근육들과 어깨주위근들의 근활성도를 조사하지 못 해서 목 주변 근육들과 어깨주위근들이 연구결과에 미치는 영향을 통제하지 못하였다. 따라서 어깨가쪽돌림 시 목의 돌림 방향에 따른 어깨뼈 움직임에 작용되는 협력근과 대항근의 운동학적 역할을 분 석하는데 한계가 있었다. 그러므로 추후 이러한 제한점을 개선하여 추가 연구를 수행한다면 보다 과학적인 운동학적 분석이 될 것으로 생각된다.

본 연구는 정상성인을 대상으로 엎드린 자세에서 어깨가쪽돌림 운동을 할 때 목의 돌림 방향이 위등세모근과 아래등세모근의 근활 성도에 어떻게 영향을 미치는지를 알아보았다. 위등세모근의 근활성 도는 어깨가쪽돌림 시 목을 중립 방향으로 했을 때와 비교하여 같은 쪽 방향으로 돌렸을 때 유의하게 감소하였으며 반대쪽으로 돌렸을
때 유의하게 증가하였다. 한편, 아래등세모근의 근활성도는 어깨가 쪽돌림 시 목을 중립방향으로 했을 때와 비교하여 같은 쪽 방향으로 돌렸을 때는 조금 증가하였고 반대쪽 방향으로 돌렸을 때는 근활성 도가 유의하게 감소하였다. 따라서 위등세모근의 과활성화와 아래등 세모근의 약화로 인한 근육불균형이나 어깨뼈 부정렬과 같은 문제 를 해결하기 위한 중재방법으로 어깨가쪽돌림 운동을 수행할 경우, 엎드린 자세에서 목을 같은쪽 방향으로 돌리는 것이 효과적인 방법 임을 알 수 있었다. 본 연구의 결과는 허리통증과 같은 기능적인 문제 로 인해 앉거나 서서 어깨 운동하기 힘든 실제 환자를 대상으로 하는 연구의 기초자료로 활용될 수 있을 것이다.

\section{REFERENCES}

1. Tepper M, Vollenbroek-Hutten MMR, Hermens HJ et al. The effect of an ergonomic computer device on muscle activity of the upper trapezius muscle during typing. Appl Ergon. 2003;34(2):125-30.

2. Choi JY, Jang JH, Oh JS. Effects of passive scapular alignment on electromyographic activity of trapezius in people with shortness of pectoralis minor muscle. Phys Ther Kor. 2012;19(2):12-9.

3. Cools AM, Declercq DC, Cambier NN et al. Trapezius activity and intramuscular balance during isokinetic exercise in overhead athletes with impingement symptoms. Scand J Med Sci Sports. 2007;17(1):25-33.

4. Lin JJ, Wu YT, Wang SF et al. Trapezius muscle imbalance in individuals suffering from frozen shoulder syndrome. Clin Rheumatol. 2005;24(6): 569-75.

5. Ki HS, Kwon OY, Yi CH et al. Effects of the scapular taping on the muscle activity of the scapula rotators and pain in subjects with upper trapezius pain. Phys Ther Kor. 2010;17(1):77-85.

6. Chester R, Smith TO, Hooper L et al. The impact of subacromial impingement syndrome on muscle activity patterns of the shoulder complex: systematic review of electromyographic studies. BMC Musculoskelet Disord. 2010;11:45.

7. Ludewig PM, Cook TM. Alterations in shoulder kinematics and associated muscle activity in people with symptoms of shoulder impingement. Phys Ther. 2000;80(3):276-91.

8. Hinterwimmer S, Von Eisenhart-Rothe R, Siebert M et al. Influence of adducting and abducting muscle forces on the subacromial space width. Med Sci Sports Exerc. 2003;35(12):2055-99.

9. Kibler WB, Sciascia AD, Uhl TL et al. Electromyographic analysis of specific exercises for control in early phases of shoulder rehabilitation. Am J Sports Med. 2008;36(9):1789-98.

10. Decker MJ, Hintermeister RA, Faber KJ et al. Serratus anterior muscle activity during selected rehabilitation exercises. Am J Sports Med. 1999; 27(6):784-91.

11. Arlotta M, LoVasco G, McLean L. Selective recruitment of the lower fibers of the trapezius muscle. J Electromyogr Kinesiol. 2011;21(3):40310 .

12. Ekstrom RA, Donatelli RA, Soderberg GL. Surface electromyographic analysis of exercises for the trapezius and serratus anterior muscles. Orthop Sports Phys Ther. 2003;33(5):247-58. 
13. Cools AM, Witvrouw EE, Declercq GA et al. Scapular muscle recruitment patterns: trapezius muscle latency with and without impingement symptoms. Am J Sports Med. 2003;31(4):542-9.

14. Seo GJ, Park JW, Kwon YH. Comparison of the electromyographic activity in the lower trapezius muscle according to four different types of exercises in healthy adults. J Kor Phys Ther. 2019;31(2):134-9.

15. Alizadehkhaiyat O, Hawkes DH, Kemp GJ et al. Electromyographic analysis of the shoulder girdle musculature during external rotation exercises. Orthop J Sports Med. 2015;3(11):1-9.

16. Park SI, Chae JY, Kim HH et al. The Effects of the position of ipsilateral neck rotation on the inhibition of the upper trapezius muscle during lower trapezius exercises. Phys Ther Kor. 2016;23(1):65-71.

17. Kendall FP, McCreary EK, Provance PG et al. Muscles: testing and function, with posture and pain. 5th ed. Baltimore, MD, Lippincott Williams and Wilkins, 2005.

18. Hwang TY, Song HS, Lee NY. Comparison of multimodal posture of healthy adults on the usage rate of the superficial neck muscles during head and neck rotation. J Korean Soc Phys Med. 2016;11(2):41-52.

19. Kim JS, Kang SY, Joa KH. Quantitative electromyographic analysis of scalenus medius and upper trapezius muscles during neck motion. J Korean Acad Rehabil Med. 2000;24(6):1104-09.
20. Yong JH, Weon JH. Comparison of the EMG activities of scapular upward rotators and other scapular muscles among three lower trapezius strengthening exercises. Phys Ther Kor. 2013;20(3):27-35.

21. Thompson LDV. Effects of age and training on skeletal muscle physiology and performance. Phys Ther. 1994;74(1):71-81.

22. De Mey K, Danneels L, Cagnie B et al. Kinetic chain influence on upper and lower trapezius muscle activation during eight variations of a scapular retraction exercise in overhead athletes. J Sci Med Sport. 2013;16(1): 65-70.

23. Smith M, Sparkes V, Busse M et al. Upper and lower trapezius muscle activity in subjects with subacromial impingement symptoms: is there imbalance and can taping change it? Phys Ther Sport. 2009;10(2):45-50.

24. Reinold MM, Escamilla RF, Wilk KE. Current concepts in the scientific and clinical rationale behind exercises for glenohumeral and scapulothoracic musculature. J Orthop Sports Phys Ther. 2009;39(2):105-17.

25. Sahrmann SA. Diagnosis and treatment of movement impairment syndrome. Elsevier Health Sciences, 2001.

26. Lunnen JD, Yack J, LeVeau BF. Relationship between muscle length, length, muscle activity, and torque of the hamstring muscles. Phys Ther. 1981;61(2):190-5. 